\title{
Investigations of dielectric and semiconductor oxides obtained by Atomic Layer Deposition method for transparent electronic sensor devices
}

\author{
S. Gieraltowska ${ }^{1}$, L. Wachnicki ${ }^{1}$, B.S. Witkowski ${ }^{1}$, M. Godlewski $^{1,2}$, E. Guziewicz ${ }^{1}$ \\ ${ }^{1}$ Polish Academy of Sciences, Institute of Physics, \\ al. Lotników 32/46, Warszawa 02-668, Poland \\ sgieral@ifpan.edu.pl \\ ${ }^{2}$ Cardinal Stefan Wyszynski University, College of Science, \\ Department of Mathematics and Natural Sciences, Warszawa, Poland
}

\begin{abstract}
:
We have obtained the transparent structures on glass and quartz with all oxide elements deposited by the Atomic Layer Deposition (ALD) technique. Use of ALD is an important factor for sensor device manufacturing, because of simplicity and low costs of fabrication. Our work was focused on the optimization of deposition parameters of composite dielectric layers consisting of $\mathrm{Al}_{2} \mathrm{O}_{3}, \mathrm{HfO}_{2}, \mathrm{ZrO}_{2}$ and of $\mathrm{ZnO}$ semiconductor layers. These layers were then used for construction of transparent thin film transistor structures and of transparent thin film capacitor structures, with $\mathrm{ZnO}$ as a channel and a gate layer. The sensor structures were obtained at low temperature (no more than $100^{\circ} \mathrm{C}$ ). These transparent structures work at room temperature and show sensor behavior to chemical.
\end{abstract}

Key words: ALD method, high-k oxides, zinc oxides, TTFT, sensor

\begin{abstract}
Introduction
High-k oxides as insulator layers and zinc oxide $(\mathrm{ZnO})$ as semiconductor layers are the most promising candidates for a next generation of thin film transparent electronic devices and for applications in sensors and cross-bar memories, see e.g. references [1-6]. Wide band gap semiconductor oxides and insulating oxides are of great interest due to their simple fabrication processes, low costs and high sensitivity to environment effects [7-8].
\end{abstract}

High-k oxides such as $\mathrm{Al}_{2} \mathrm{O}_{3}, \mathrm{ZrO}_{2}, \mathrm{HfO}_{2}, \mathrm{SrO}$, $\mathrm{MgO}, \quad \mathrm{La}_{2} \mathrm{O}_{3}, \quad \mathrm{TiO}_{2}$ have already been demonstrated as prospective transparent insulating materials with a high dielectric constants and a wide band gap. These properties make possible to achieve desirable electrical characteristics, most off all, a low leakage current [8]. Thus, these high-k oxides are seen as the alternatives to $\mathrm{SiO}_{2}$ in commercial electronics, as $\mathrm{HfO}_{2}$ has already been used in $45 \mathrm{~nm}$ node processors [11].

$\mathrm{ZnO}$ is a promising transparent semiconductor oxide for transparent electronics applications, with a wide band gap of $3.37 \mathrm{eV}$ at room temperature and high transparency in the visible range [9]. Consequently, $\mathrm{ZnO}$ has been used as a transistor channel and/or a gate material in transparent transistors $[3,10]$.

The operation characteristics of sensors based on semiconducting oxides are determined by the electrical properties of the material used. The conductivity of the sensing material changes upon surface adsorption and desorption of gases or molecules of chemical solutions. We can thus follow conductivity changes in the sensing material upon exposure to a chemical solvents or specific gases. Such changes can be large if a highly sensitive semiconducting material is used.

In this work we describe the fabrication of transparent TFT structures. We believe that such a structure, which is compatible with transparent electronics and displays, allows construction of a whole device on one substrate. We deposited all key elements (dielectric oxides as an insulator material and $\mathrm{ZnO}$ as a channel and a gate) using the ALD growth method. These materials were deposited at growth temperature below $100^{\circ} \mathrm{C}$. The obtained the thin film transistor structure with a gate at bottom and with a top channel is shown in Fig.1. This construction of the $\mathrm{ZnO}$ TTFTs was checked for sensor applications. 


\section{Experimental details}

The oxides were deposited by the Atomic Layer Deposition technique in the Savannah-100 reactor from the Cambridge NanoTech Company. Glass, quartz $\left(\mathrm{SiO}_{2}\right)$ and n-type silicon ( $\mathrm{n}-\mathrm{Si}$ ) were used as substrates. These substrates were cleaned in an ultrasonic bath with solvents (trichloroethylene, acetone and isopropanol) and de-ionized water before the deposition. The main advantage of the ALD method is a self limitation and a sequential growth process, which allows for use of very reactive precursors and deposition at relatively low temperatures. In the present work we used tetrakis(dimethylamido)hafnium as a hafnium precursor, trimethylaluminum as an aluminum precursor, tetrakis(dimethylamido) zirconium as a zirconium precursor, diethylzinc as a zinc precursor, and de-ionized water or ammonia water as an oxygen precursor. The oxides were deposited at very low temperature (no more than $100^{\circ} \mathrm{C}$ ) by double-exchange chemical reactions:

$\mathrm{Hf}\left[\left(\mathrm{CH}_{3}\right)_{2} \mathrm{~N}\right]_{4}+2 \mathrm{H}_{2} \mathrm{O} \rightarrow \mathrm{HfO}_{2}+4 \mathrm{HN}\left(\mathrm{CH}_{3}\right)_{2}$
$2 \mathrm{Al}\left(\mathrm{CH}_{3}\right)_{3}+3 \mathrm{H}_{2} \mathrm{O} \rightarrow \mathrm{Al}_{2} \mathrm{O}_{3}+6 \mathrm{CH}_{4}$
$\mathrm{Zr}\left[\left(\mathrm{CH}_{3}\right)_{2} \mathrm{~N}\right]_{4}+2 \mathrm{H}_{2} \mathrm{O} \rightarrow \mathrm{ZrO}_{2}+4 \mathrm{HN}\left(\mathrm{CH}_{3}\right)_{2}$

and

$\mathrm{Zn}\left(\mathrm{C}_{2} \mathrm{H}_{5}\right)_{2}+\mathrm{NH}_{3} \cdot 2 \mathrm{H}_{2} \mathrm{O} \rightarrow \mathrm{ZnO}+2\left(\mathrm{C}_{2} \mathrm{H}_{5}\right)_{2}+\mathrm{NH}_{3}$.

In most of the ALD processes we limited the growth temperature to $100^{\circ} \mathrm{C}$, taking into account the possibility of deposition of thin films on transparent and elastic (polymers) substrates. This opens the chance of production very simply and inexpensive electronic sensors. Films thickness scaled with a number of the ALD cycles. Typical growth rates were about $0.10 \mathrm{~nm}$ per cycle for $\mathrm{Al}_{2} \mathrm{O}_{3}$, $0.14 \mathrm{~nm}$ for $\mathrm{HfO}_{2}, 0.09 \mathrm{~nm}$ for $\mathrm{ZrO}_{2}$, and 0.18 $\mathrm{nm}$ for $\mathrm{ZnO}$. For organic precursors we used short pulses of precursors of several ms length. The structural characterization was performed by the X-ray diffraction method, using the X'Pert MPD diffractometer equipped with an X-ray mirror and a two-bounce monochromator at the incident beam. The diffracted beam was measured with a 2-dimensional Solid-State Xray Detector-PIXcel. The layers thickness was measured using the spectroscopic reflectometer Nanocalc 2000. The surface morphology was investigated by the atomic force microscopy (AFM, Bruker Dimension Icon) using the PeakForce Tapping and silicon nitride probes with sharp tips (a tip radius: 2 $\mathrm{nm})$. The images of cross-sections were taken using the scanning electron microscopy (SEM, Hitachi SU-70) at $15 \mathrm{kV}$ accelerating voltage. Optical transmission spectra were measured with the Solar CM2203 spectrometer. I-V electrical characterizations for a transparent thin film transistor (TTFTs) (see Fig. 1.) and a capacitor (TTFCs) structure were performed using Keithley 2601A and 2636A electrometers. In the latter case the structure performance was investigated for gate dielectrics deposited on semiconductor substrates: $\mathrm{n}-\mathrm{Si}$ and $\mathrm{ZnO} / \mathrm{SiO}_{2}$ ( $\mathrm{ZnO}$ layers were grown by ALD at temperature of $100^{\circ} \mathrm{C}$ with thickness of $100 \mathrm{~nm}$ ). In these test structures a $10 \mathrm{~nm} \mathrm{Ti/40} \mathrm{nm} \mathrm{Au} \mathrm{gate}$ electrode was deposited by sputtering using a photoresist mask removed then by a lift-off process in solvents. Tests were performed on a series of metal-oxide-semiconductor (MOS) type capacitors not only to check reliability of the results, but also uniformity of a material deposition. The area of our capacitors was about $0.09 \mathrm{~cm}^{2}$.

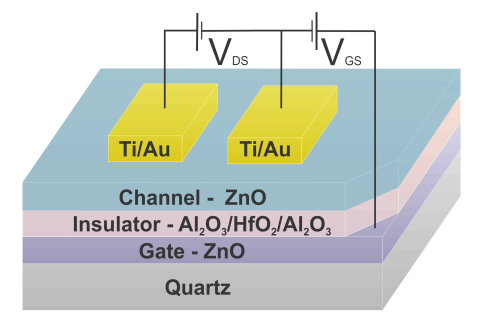

Fig. 1. The schematic cross-section of the TTFT sensor structure on a transparent substrate, with composite layers $A H A$ as an insulator and $\mathrm{ZnO}$ as a channel and a gate. All oxides were deposited in the ALD system.

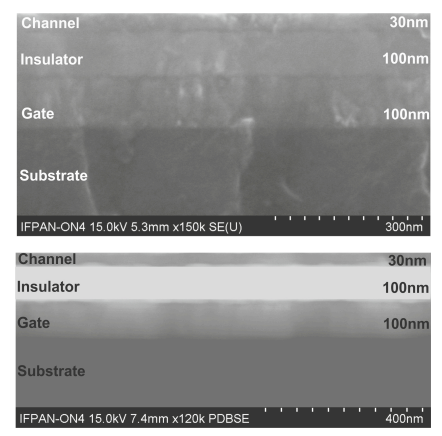

Fig. 2. Cross-section SEM images of the TTFT sensor structure with composite layers AHA as an insulator and $\mathrm{ZnO}$ as a channel and a gate. Images were taken with secondary electrons (top) and back scatter electrons (bottom) detectors.

\section{Results and discussion}

In this study, we used the Atomic Layer Deposition method which was originally developed in the 70s [12]. Nowadays, this technique is used in semiconductors industry (Intel Company) for deposition of gate dielectrics in new generations of integrated circuits [11]. Reproducibility, uniformity of films on large areas with deposition control at the nanometer scale, and low growth temperature make the ALD an ideal candidate for simple 
and low cost deposition of various transparent dielectrics and semiconductors, for coating of transparent substrates, and for production of electronic sensor devices.

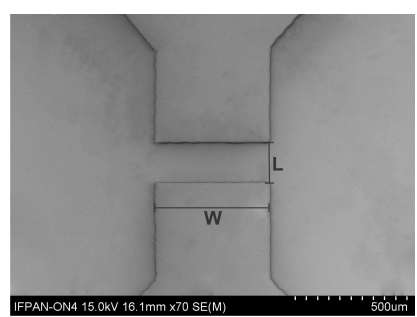

Fig. 3. SEM images of the source and drain Ohmic contacts Ti/Au and ZnO channel layer, with $500 \mu \mathrm{m}$ channel width (W) and $200 \mu \mathrm{m}$ channel length (L).

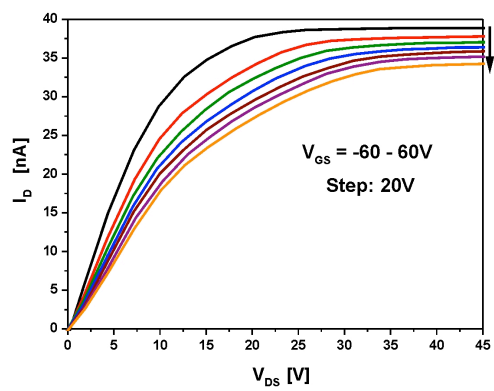

Fig. 4. Drain current $\left(I_{D}\right)$ vs drain voltage $\left(V_{D S}\right)$ characteristics of investigated TTFT sensor structures.

We aimed to obtain high-k thin dielectric films by the ALD method with the optimized electrical parameters, since these components strongly affect TTFT performance. We found that an optimal insulator consists of a composite layer of either $\mathrm{Al}_{2} \mathrm{O}_{3} / \mathrm{HfO}_{2} / \mathrm{Al}_{2} \mathrm{O}_{3}$ (labeled here as $\mathrm{AHA})(10 \mathrm{~nm} / 80 \mathrm{~nm} / 10 \mathrm{~nm})$, or $\mathrm{Al}_{2} \mathrm{O}_{3} / \mathrm{ZrO}_{2} / \mathrm{HfO}_{2} /-$ $\mathrm{Al}_{2} \mathrm{O}_{3} \quad(10 \mathrm{~nm} /(10 \mathrm{~nm} / 10 \mathrm{~nm}) \times 8 / 10 \mathrm{~nm}) \quad$ (labeled here as $A Z H A)$. These structures are characterized by atomically smooth surfaces, an amorphous structure, a dielectric strength of about $4 \mathrm{MV} / \mathrm{cm}$ on a $\mathrm{Si}$ substrate and above 10 $\mathrm{MV} / \mathrm{cm}$ on a transparent $\mathrm{ZnO} / \mathrm{SiO}_{2}$ substrate, a low leakage current below $5^{*} 10^{-8} \mathrm{~A} / \mathrm{cm}^{2}$ for $\mathrm{AHA}$ on $\mathrm{Si}$, below $5^{*} 10^{-7} \mathrm{~A} / \mathrm{cm}^{2}$ for AZHA on $\mathrm{Si}$, and below $10^{-8} \mathrm{~A} / \mathrm{cm}^{2}$ for $\mathrm{AHA}$ on $\mathrm{ZnO} / \mathrm{SiO}_{2}$ substrate at $1 \mathrm{~V}$, relatively high dielectric constant of $19 \pm 3$ (as compared to $\mathrm{ZrO}_{2} \mathrm{k}=23 \pm 3$, $\mathrm{HfO}_{2} \mathrm{k}=21 \pm 3, \mathrm{Al}_{2} \mathrm{O}_{3} \mathrm{k}=10 \pm 3$ ) and a large band gap sufficient to yield a band offset with respect to $\mathrm{ZnO}$, as required for practical applications, as already reported in our paper [13]. The resulting dielectric constants are favorably comparable with parameters reported in the literature with optimal dielectrics for MOS structures on a $\mathrm{Si}$ substrate obtained below $100^{\circ} \mathrm{C}$ [8]. We prepared the TTFT sensor structures deposited by ALD on a transparent quartz substrate (see Fig. 1. and 2.). In this TTFT sensor structure,
AHA was used as an insulating material, because AHA has a smoother surface and a lower leakage current than AZHA layers. Fig. 2. shows the cross-section SEM images of the sensor structure deposited on a transparent substrate, in which we used the $\mathrm{ZnO}$ thin film not only as a channel material, but also as a gate electrode (100 nm thick). The thickness of a composite high-k dielectric layer was $100 \mathrm{~nm}$. The deposition temperature of the high-k oxides was $85^{\circ} \mathrm{C}$. On the top of a dielectric layer a $\mathrm{ZnO}$ film was deposited as a channel material. Layer thickness was $30 \mathrm{~nm}$ and the growth temperature was $80^{\circ} \mathrm{C}$. The results shown in Figs. 3 and 4 were obtained for a similar structure in which the source and drain Ohmic contacts ( $4 \mathrm{~nm} \mathrm{Ti} / 10 \mathrm{~nm} \mathrm{Au}$ ) were obtained by sputtering. Device dimensions, relatively large for sensor purposes, were as follows: $500 \mu \mathrm{m}$ channel width (W) and $200 \mu \mathrm{m}$ channel length (L) (see Fig. 3.).

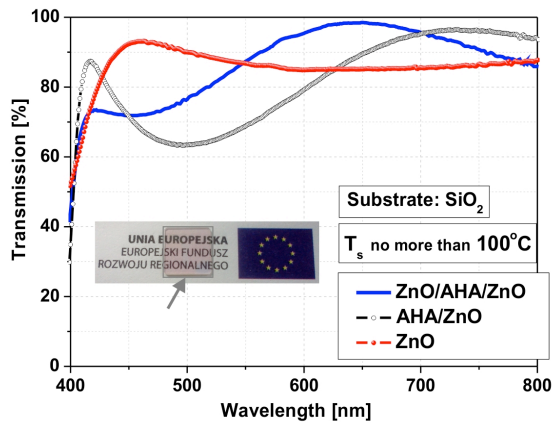

Fig. 5. Optical transmission spectra of the $\mathrm{ZnO} / q u a r t z$, AHA/ZnO/quartz TTFC and ZnO/AHA/$\mathrm{ZnO}$ /quartz TTFT structures. The inset shows a photograph of a $1 \mathrm{~cm} \times 1 \mathrm{~cm} \mathrm{SiO}{ }_{2}$ substrate with the structure studied, placed on the text with the European Union logo, to demonstrate that our structure is fully transparent to a visible light.

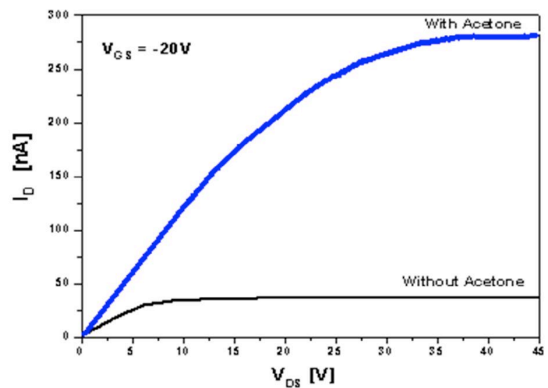

Fig. 6. The typical response of $\mathrm{ZnO}$-based ( $\mathrm{ZnO}$ as a channel) TTFT sensor structure - drain current $\left(I_{D}\right)$ vs drain voltage $\left(V_{D S}\right)$ measured at $-20 \mathrm{~V}$ of gate voltage - to application of acetone.

Fig. 5. demonstrates the optical transmittance spectrum of structures on transparent substrates measured in the wavelength range between 400 and $800 \mathrm{~nm}$. The average optical 
transmission in the visible range of the spectrum is over $85 \%$.

The drain current characteristics $\left(I_{D}\right)$ as a function of source-drain voltage $\left(V_{D S}\right)$ between 0 and $45 \mathrm{~V}$ for various values of gate voltages $\left(\mathrm{V}_{\mathrm{GS}},-60 \mathrm{~V}-+60 \mathrm{~V}\right)$ are shown in Fig. 4 for a TTFT sensor structure without the presence of chemical solutions. The output characteristics exhibit clear current saturation and pinch off behavior, as evidenced by the fact that the slope of each $I_{D}$ curves is flat for large $V_{D S}$. This indicates that the entire thickness of the $\mathrm{ZnO}$ channel can be eventually depleted of free electrons [14].

The proposed $\mathrm{ZnO}$ channel based TTFT sensor was used to detect different chemical solutions such as acetone, isopropanol and ethanol. These solutions were put on the $\mathrm{ZnO}$ channel surfaces. Fig. 6. exhibits the typical $I_{D}-V_{D S}$ electrical response of the fabricated TTFT chemical sensor based on $\mathrm{ZnO}$ channel. Device characteristics were taken in the absence and presence of solution droplet (acetone). It is obvious from the figure that by applying a given chemical solution, i.e. acetone, a significant enhancement in current and clear current saturation and pinch off behavior are observed, which reflects a high sensitivity of $\mathrm{ZnO}$ layers as channel, and also a reliable operation of TTFT-based sensor. $\mathrm{ZnO}$ is a sensing material and possesses fast electron exchange properties [1], hence it is believed that due to these properties a rapid increase of channel conductivity was observed in the presence of chemical solutions. In addition to this, the increase in the drain current can be attributed to the discharge of the trapped electrons into the conduction band. Transparent sensors operate at room temperature and are reset to the original conductivity of $\mathrm{ZnO}$ channel within a few minutes, without any surface treatment or heating. A conductivity increase was observed for several tested solvents and alcohol.

\section{Conclusion}

In conclusion, we fabricated TTFT sensor structures with composite dielectric layers consisting of $\mathrm{Al}_{2} \mathrm{O}_{3}, \mathrm{HfO}_{2}$ as an insulator layer and $\mathrm{ZnO}$ as a channel and a gate layer. The structures were deposited by ALD at low temperature (no more than $100^{\circ} \mathrm{C}$ ) on a transparent substrate. These structures show sensor behavior to different chemical solvents and alcohol. Importantly, the simplicity of the structure and low costs of fabrication make them attractive. Transparent sensor structures operate at room temperature and heating and processing is not required to reset the devices. We thus conclude that the reproducible operation at room temperature make them ideal for novel electronic sensor applications. Importantly, the whole sensor structure, with $\mathrm{ZnO}$ and high-k oxides, can be fabricated by the same deposition method without moving the structure from the reactor. The obtained TTFTs deposited on transparent substrates show high average transmittance of over $85 \%$ at visible light. Thus, $\mathrm{ZnO} /$ high-k dielectric TTFT sensors are also promising for use in transparent electronics devices.

\section{Acknowledgements}

The research was partially supported by the European Union within European Regional Development Fund through grant Innovative Economy (POIG.01.01.02-00-008/08) and within European Social Fund through Human Capital Programme and local authorities (Samorząd Województwa Mazowieckiego).

\section{References}

[1] Hadis Morkoç, Ümit Özgür, Zinc Oxide: Fundamentals, Materials and Device Technology, (2009); ISBN: 978-3-527-40813-9

[2] J.F. Wager, Science 300, 1245 (2003); DOI: 10.1126/science. 1085276

[3] J.F. Wager, D.A. Keszler, R.E. Presley, Transparent Electronics, Springer, New York (2008); ISBN: 978-0-387-72341-9

[4] S. Masuda, K. Kitamura, Y. Okumura, S. Miyatake, H. Tabata, T. Kawai, J. Appl. Phys. 93, 1624 (2003); doi: 10.1063/1.1534627

[5] R.L. Hoffman, B.J. Norris, J.F. Wager, Appl. Phys. Lett. 82, 733 (2003); doi: 10.1063/1.1542677

[6] P.F. Carcia, R.S. McLean, M.H. Reilly, G. Nunes Jr., Appl. Phys. Lett. 82, 1117 (2003); doi: 10.1063/1.1553997

[7] G. Eranna, B.C. Joshi, D.P. Runthala, R.P. Gupta Crit. Rev. Solid State Mater. Sci. 29, 111-188 (2004); doi: 10.1080/10408430490888977

[8] J. Robertson, Eur. Phys. J. Appl. Phys. 28 265291 (2004); doi: 10.1051/epjap:2004206

[9] C. Klingshirn, Phys. Status Solidi B 244, 3027 (2007); doi: 10.1002/pssb.200743072

[10] S.-H.K. Park, C.-S. Hwang, H.Y. Jeong, H.Y. Chu, K.I. Cho, Electrochem. Solid-State Lett. 11, H10 (2008) doi: 10.1149/1.2801017

[11] G. E. Moore, Electronics 38, 8 (1965); doi: 10.1109/JPROC.1998.658762

[12] T. Suntola, J. Antson, US Patent 4058430 (1977).

[13] S. Gieraltowska, L. Wachnicki, B.S. Witkowski, M. Godlewski, E. Guziewicz, Thin Solid Films, online (2011); doi:10.1016/j.tsf.2011.10.151, 2011

[14] E. Fortunato, P. Barquinha, A. Pimentel, A. Goncalves, A. Marques, L. Pereria, R. Martins, Adv. Mater. 17, 590 (2005); doi: 10.1002/adma.200400368 